See discussions, stats, and author profiles for this publication at: https://www.researchgate.net/publication/338192747

\title{
Early learning opportunities for children at risk of social exclusion. Opening the black box of preschool practice
}

Article in European Early Childhood Education Research Journal · December 2019

DOI: 10.1080/1350293x.2020.1707360

CITATIONS

0

3 authors:

(1)

Brecht Peleman

Ghent University

24 PUBLICATIONS 21 CITATIONS

SEE PROFILE

Piet Van Avermaet

Ghent University

104 PUBLICATIONS 802 CITATIONS

SEE PROFILE

Some of the authors of this publication are also working on these related projects:
READS

58

Michel Vandenbroeck

Ghent University

173 PUBLICATIONS 1,329 CITATIONS

SEE PROFILE

Teachers' collaborative practices in developing inclusive education View project 
Early learning opportunities for children at risk of social exclusion. Inside the black box of preschool practice.

Brecht Peleman $^{\mathrm{a} *}$, Michel Vandenbroeck ${ }^{\mathrm{a}}$ and Piet Van Avermaet ${ }^{\mathrm{b}}$

${ }^{a}$ Ghent University, Department of Social Work and Social Pedagogy, Belgium;

${ }^{b}$ GhentUniversiy, Centre for Diversity and Learning, Linguistics Department, Belgium

*H. Dunantlaan 2,

9000 Ghent,

Belgium

$0032(0) 92649127$

Brecht.Peleman@,UGent.be

Please check against the final version.

The final version was published as Brecht Peleman, Michel Vandenbroeck \& Piet Van Avermaet (2019):

Early learning opportunities for children at risk of social exclusion. Opening the black box of preschool practice, European Early Childhood Education Research Journal, DOI: 10.1080/1350293X.2020.1707360

To link to this article: https://doi.org/10.1080/1350293X.2020.1707360

Funding details:

This project was funded by the Child poverty fund of the FWO (the Research Foundation Flanders)

Declaration of interest statement:

There was no conflict of interest 


\title{
Early learning opportunities for children at risk of social exclusion. Inside the black box of preschool practice.
}

\begin{abstract}
Influenced by a growing number of longitudinal studies showing positive effects of preschool attendance, ECEC is framed as a potential equaliser of opportunities, especially to the benefit of children at risk of social exclusion and children from families with a migration background in particular. The preschool age is considered a crucial period for young children's language acquisition and there is consensus that stimulating and supportive teacher-child interactions in enriched classroom settings are paramount. However, research on daily interactions in contexts of diversity and multilingualism is still scarce and, as a result, the qualitative processes by which the preschool may be equalizing or reproducing the gap, remain under-theorized. In the present study, eight children living in poverty (most of whom had a migrant background) were closely followed during their first year in pre-primary education through detailed video-observations of daily interactions. The results of the in-depth quantitative and qualitative analysis of 54 activities are presented. The results show that both the quantity and the quality of individual verbal interactions were low. The children were hardly addressed individually by the teacher, the number of verbal learning opportunities was limited and there were few opportunities for language production. The majority of the utterances of the teacher towards the children was directive and disciplining in nature and the home languages of the children were not valued. The few examples where teachers used a home language in individual interactions were intended to better direct the behavior of the child. By closely observing individual interactions, unintended mechanisms that hinder an equal distribution of learning opportunities were found in each of the four classes. As such, the results of the study suggest that preschools may also be confirming or even broadening existing inequalities.
\end{abstract}

Keywords: preschool, teacher-child interactions, learning opportunities, transitions, multilingualism 


\section{Introduction}

\section{Quality ECEC experiences}

Children from families with a migration background are often considered to particularly benefit more from the positive impact of Early Childhood Education and Care (ECEC)(Brilli, Del Boca, \& Pronzato, 2011; Felfe \& Lalive, 2018). As a result, ECEC is framed as a potential equaliser of opportunities (Marope\&Kaga, 2015; OECD, 2017; European Commission, 2018). However, these beneficial effects can only be achieved in contexts of high-quality provision. The ongoing EPPSE ${ }^{1}$ study showed that in high-quality settings, all children make more progress in their development and that this effect can last up to secondary education (Sammons et al., 2012). However, not all studies draw similar conclusions. For example, research in France (Caille, 2001) has shown that - when controlled for socioeconomic background - entering preschool at two years old instead of three had no significant positive effect on later school success. In the same line, a recent study in the Flemish community of Belgium (Authors Own, in press) has found mixed general effects of early universal preschool participation on academic outcomes measured at nine years old: a significant small positive effect for science, but not for reading in the language of schooling. These studies add up to the understanding that not only the frequency of preschool participation should be considered, but also its process quality. However, a Danish study by Jensen, Holm, and Bremberg (2013) has found that raising the quality of preschool through in-service training of teachers increased the gap between children of higher and lower SES. Given these somewhat contrasting findings, it is crucial to understand how the quality of preschool education is constructed and implemented by teachers and school staff and how these conceptions of process quality relate to the experiences of children and parents living in poverty or at risk of social exclusion.

\footnotetext{
${ }^{1}$ The Effective Pre-School, Primary and Secondary Education project. Study on the effectiveness of early years education. https://www.ucl.ac.uk/ioe/research-projects/2018/oct/effective-pre-school-primaryand-secondary-education-project-eppse
} 


\section{Adult-child interactions and language development}

The preschool age is a crucial period for young children's language acquisition(Becker, Klein, \& Biedinger, 2013; Magnuson, Meyers, Ruhm, \& Waldfogel, 2004). There is consensus in this vein that process quality is crucial (Slot, 2018) and that it is characterized by stimulating and supportive teacher-child interactions in enriched classroom settings (Sabol, Hong, Pianta, \& Burchinal, 2013). This consent is rooted in socio-constructivist learning theories (Hedges \& Cullen, 2012) which state that children learn by acting and communicating in everyday situations with their parents, other educators and other children. The acquisition of skills in general and language skills in particular arises from a child's desire to understand its environment and to share experiences and emotions with meaningful others. In these interactions, the role of the adult is crucial. The quality of the adult-child interaction in ECEC services determines the way in which the development of the children is fostered (Slot, Lerkkanen, \& Leseman, 2015). This is especially true for language acquisition (Ramirez-Esparza, Garcia-Sierra, \& Kuhl, 2014). Establishing a high-quality language environment asks for a rich, natural and spontaneous language input that actively stimulates children to use language (language production) and to articulate actions and thinking processes (La Paro, Hamre, \& Pianta, 2012; Loman, Moons, \& Versteden, 2012). The language used by the adult should be adequately abstract but comprehensible in the way it connects speech and actions (Bogaert et al., 2015). Moreover, it should depart from the lifeworld and experiences of the children themselves (Ramaut et al., 2013). To effectuate this in the context of a preschool class, it is necessary that children are offered many rich opportunities to practice and that they receive supportive feedback on their verbal utterances (DeKeyser, 2007; Ellis, 2005). In addition, when the multilingual repertoire of the child is acknowledged, valued and used, school success can be improved (García \& Wei, 2014; Jaffe, 2003; Moodley, 2007; Olivares \& Lemberger, 2002; Olmedo, 2003; Ramaut et al., 2013). A key aspect for migrant children, is the valorisation of multilingualism as an 'added value' and 'resource', rather than a 'problem' or 'deficit' (Authors Own, 2014). In contrast to these findings, research on the daily interactions in contexts of diversity and multilingualism is still scarce and, as a result, the qualitative processes by which the preschool may be equalizing or broadening the gap, remain under-theorized. Too little is yet known about the first lived experiences of migrant children in preschool. In our study, we closely followed eight children 
during their first year in preschool, leading to detailed quantitative and qualitative analyses of daily interactions.

\section{Research context}

The Flemish Community of Belgium has the highest enrolment rates at one of the earliest ages (more than $98 \%$ of all children aged $3-5$ years old are enrolled) among OECD-countries (Department of Education and Training, 2016). Despite quasi universal preschool enrolment, there remains a persistent achievement gap between children with and without a migrant background and between children who speak Dutch at home and those who have another home language(Danhier \& Jacobs, 2017). Therefore, it is a compelling case to study qualitative processes in preschool and to disclose how these processes may or may not reduce inequalities (Jacobs, Rea, Teney, Callier, \& Lothaire, 2009). Detailed observations of the lived experiences and early preschool learning opportunities of children at risk in these setting may contribute to unravel what precisely defines high-quality interactions in contexts of cultural and socioeconomic diversity. In so doing, they may help to understand early reproduction of social inequalities. We closely studied real life experiences in four preschool classes with a mixed method approach, integrating quantitative and qualitative approaches.

\section{Methodology}

\section{Sample}

Our study looked into the first learning experiences of eight children entering pre-primary education, during one year, starting from the very first day they arrived in the classroom. A purposive sample (Robson, 2002) of four cases was built, each case being a classroom of the youngest children in preschool (i.e. an entry class for children from 2,5 to 4 years old). In line with the majority of Flemish preschools, the entry classes from our sample are characterized by a group of more than 20 children of the same age-span under the responsibility of one single teacher who is sometimes supported by an assistant for one or a few hours per week.

In each case, two children from poor or migrant families were selected as focal children. Each case was selected in a different school to maximise diversity of contexts in the sample. The four cases represent areas in the Flemish community of Belgium known for their high percentages of families living in poverty, with $30 \%$ to $60 \%$ of enrolled children belonging to at 
risk populations. 'At risk' is defined by the Flemish community by the following indicators: low income (using a school allowance), low educational level of the mother and home language different from Dutch. All eight focal children were signalled by the school board as belonging to one or more of these indicators and seven of them belonged to a language minority.

\section{Data collection}

The data collection consisted of extensive video observations during a period of 11 months. Each of the four cases was visited 8 to 13 times for 2 to 4 hours by one or two researchers capturing the everyday experiences of the focal children on video. Observations were done with two cameras, one camera following a focal child and a second steady camera overseeing the group. Additional field notes were made to capture as much of the actual experiences as possible. In total, 44 observational moments took place, which resulted in over 166 hours of video footage. Informed consent was obtained from all parents in the selected classes, as well as from the staff and management of the schools. The study was coherent with the ethical protocol of the Faculty of the first and second authors.

\section{Procedure}

All video recordings were transcribed and coded in a custom made spreadsheet, distinguishing the different activities and specifying in which activity the focal children were involved. Each activity was timed, allowing to compute how much time was spent in each of the activities, how time was divided among the activities and how much time children had to wait in silence.

For the in-depth analysis of the learning experiences of the children, we selected six types of activities: Circle time (whole group activity in a designated area in the classroom); Free play (individual and small group activity in different corners of the classroom); Snack time; Changing clothes and arranging satchels; Playtime in the playground (free play outside the classroom); and Lunch at noon (outside the classroom, in the lunchroom of the school). For each of the cases, we selected a variety of these six types of activities where both of the focal children were involved. This resulted in a selection of 79 activities (31,5 hours of video recording) eligible for analysis. All verbal utterances (from staff as well as form the children) were transcribed verbatim and their duration was quantified to the second. When a pause of two seconds occurred in between a word sequence, we coded this as two distinct utterances. During playtime on the playground and during lunch break, the children of the four schools were together with a large group of children from 
other classes, playing outside or having a meal together in a large lunch room. This coincided with much arousal and noise, which made the recording of each individual utterance unreliable. Therefore, the individual utterances of the focal children during these activities lacked verbatim transcriptions. This resulted in a full coding of 54 activities instead of 79 .

\section{Analysis}

We quantitatively analysed the number and duration of all verbal utterances during each of the 54 activities, on the level of the whole class as well as on the level of the individual focal child. All verbal utterances were classified and counted according to their direction: teacherchild (TC); child - teacher (CT); teacher - teacher (TT) and child - child (CC). Their length was timed to the second.

In addition, we qualitatively assessed the quality of the TC interactions with each of the eight focal children individually. Drawing on state of the art research findings on language development support and inspired by existing frameworks(e.g. Bogaert et al., 2015; Loman et al., 2012) and validated rating scales(e.g. CLASS Toddlers by La Paro et al., 2012), we focussed on three core features: language input (L.I.), opportunities for language production (L.P.) and feedback (FB). We used the following indicators for these three dimensions, based on the literature review:

[Insert Table 1: indicators for the qualitative analysis of teacher-child interactions]

The occurrence of each of the three key features was scored on a 4 point Likert scale with 0: absent; 1: limited; 2: average; and 3: frequent. Together with the quantitative coding of individual utterances, this served as the starting point for an in-depth qualitative analysis of the verbal interactions. The 54 activities serve as the unit of analysis. Table 2 presents the number of selected activities $(\mathrm{N})$ for each class and their average duration.

\section{[Insert Table 2: Overview selected activities]}

We counted the number of individual verbal interactions that involved the focal children during the four types of activities. For each class and for each activity, all utterances to and from the focal children were counted and presented according to their direction, as presented in table 3. 
The average amount of utterances is given as well as an average duration of the utterances. We particularly focused on individual interactions with the focal children as these contain the most learning opportunities. Therefore, we did not consider the utterances of the teacher to a whole group of children (e.g. in the case of group instructions such as "Okay children, it's time to clean up." being individual utterances, even if the focal children were involved in the group that was addressed by the teacher.

\section{Results}

We first sketch the quantitative results (i.e. the numbersof utterances and their length) before we make a closer analysis of their quality.

\section{Quantity of utterances}

\section{[Insert Table 3: Quantity of individual utterances]}

The focal children were hardly addressed by the teacher, they had very few utterances towards the teacher and they had even fewer verbal interactions with their peers. During circle time, snack time and clothes \& satchels utterances to and from the focal children were even scarcer.Circle time was the activity with the least utterances: apart from two exceptions (eight TC utterances for focal child 2 of class 2 and twelve TC utterances for focal child 1 of class 3 ), the focal children were addressed individually 1,5 to 4,8 times during circle time.

TC utterances were more frequent than any other interaction modes, irrespective of the type of activity. The language input was thus largely determined and initiated by the teacher. During most activities, the focal children verbally addressed the teacher only 0 to 1,5 times. Verbal interactions between children were even more scarce as nowhere more than 0,8 utterances on average were observed.

During free play moments, the number of individual verbal utterances was higher, and this was the case for all interaction modes, including peer interactions. However, the interaction patterns with the focal children differed. The language quantity during free play was largely determined by the presence or absence the teacher in the activity. When a teacher-guided activity occurred during free play moments, more expanded language input from the teacher was observed. However, while the spontaneity of free play has the potential of increased language opportunities, the focal children often did not benefit from that potential. Whether they do, depended largely on the presence and the behavior of the teacher. We found that the number of 
utterances of a teacher towards an individual child during free play was positively associated with the number of utterances of the child towards the teacher $(\mathrm{p}=.026 ; 1$-tailed). However, we foundno significant correlation between the number of utterances from the teacher to the focal child and peer utterances $(\mathrm{p}=.274 ; 1$-tailed). This suggests that the utterances of the teacher in our sample did not foster interactions between children.

\section{Quality of T-C interactions}

Table 4 gives the sum scores of the qualitative coding of the individual T-C interactions with the focal children for the three indicators Language Input (L.I.), Opportunities for Language Production (L.P.) and Feedback (FB).

[Insert Table 4: Quality of individual TC interactions]

\section{Language input (L.I.)}

The focal children experienced richer language during individual activities such as individual care moments (e.g. diaper changing) or an individual activity guided by the teacher during free play. However, these moments were short, they did not occur frequently and inherent opportunities for language-rich interactions were often not seized by the teacher. The majority of the TC utterances were directive and disciplining in nature: teachers in the four classes frequently used language to guide the organization or the management of an activity. This enabled them to structure the routine of the day and to manage the large group. Routine moments and transitions during the day often coincided with tumult and noise. This impacted on the language use of the teachers: the noisier the moment, the more the teachers used a specific and commanding language with short sentences and without invitations for interaction. This impedes learning opportunities as it hinders qualitative peer interactions as well as child-teacher interactions.

This was most explicit during clothes and satchel moments and during circle time. It was also the case during the rare moments when home languages of the focal children were used by the teacher. Although seven of the eight focal children were multilingual, the language input of the teachers was almost exclusively Dutch. In class 1 and class 2 we did not record any use of home language other than Dutch in all 28 activities. In class 3, the teacher at just one moment spoke French to focal child Huri who has a Turkish-French background. We recorded three utterances where the teacher used French, each time to control the behavior of Huri: 
"Oh, Huri, what are you doing? No, no! You are not allowed to do that. No, c'est dangereux. It's dangerous. You cannot! Now sit down nicely and quiet."

"Huri, finit. Sit down on the bench! Stop it!"

"Put it down softly, Huri. Doucement. Oui, bravo."

We also observed that group size had an influence on both the quantity and the quality of verbal interactions. This was most obvious in class 3 where the groupsize evolved from 8 children in September to 20 children in January. During circle time on September 20150911, the small group of children clearly benefited the peaceful atmosphere and mutual verbal interactions. Visibly at ease, the teacher explained the structure of the day to the children. This went very serenily. During circle in December (20151218) the group had almost doubled to 15 children. Remarkably, there was more tumult and the utterances of the teacher were more negative, directive and reprimanding.

The language input during free play differed from the other activities. In most cases, the teacher was also present at a table or in a corner to support an individual activity of a child, mostly crafts chosen by the teacher. One by one, the teacher asked the children to come to the table. She explained what the children were expected to do and she helped them getting started. During these moments, both the quantity and the quality of the individual T-C interactions was higher. However, this was not the case for each child. For example, during the four free play moments in class 4,we observed focal child Milena who was not engaged in any of these individual activities. On a total of 2 hours and 40 minutes, there were only 6 individual T-C utterances:

"Uhm, Milena." (20150907)

"Uhm, Milena, bicycles over there!" (20150907)

"You can ride the bicycle, but you have to do it over there."(20150907)

"Yes, we'll wash, Milena." (20150907)

"Here, Milena." (20150922)

"Do you want to take a look at the books, Milena? The books? Or the dolls?" (20151006) 
The utterances were all very short, had no open questions nor invitations for interaction. On the fourth free play moment, we observed no individual T-C interactions with Milena. On average, the free play moments in this class had a duration of 39,5 minutes, for the vast majority of time without any verbal learning opportunities of Milena in interaction with the teacher.

\section{Opportunities for language production (L.P.)}

The individual TC interactions showed conversational turns, mostly consisting of nothing more than a (closed) question followed by an answer. This did not enrich the conversation, nor did it stimulate the children to produce more or new vocabulary. For example, in all 13 activities (for a total of 3 hours and 51 minutes) only six open ended questions were asked to focal child Precious (class 1):

"What is that?" (during clothes \& satchels, 20150909)

"Where is your fruit, love?" (during snack time, 20150909)

"What's wrong?" (during snack time, 20150909)

"Hi Precious, what do you have there?" (during free play, 20151020)

What do you say?" (during free play, 20151020)

"How do you come to school?" (during circle time, 20160303)

These questions did not stimulate Precious to engage in a conversation. All other questions to Precious were closed questions. There was only one exceptional dialogue of more than just one question and one answer during the circle time on 20151020:

Precious: "Miss, look. Miss."

Teacher: "Hi Precious, what do you have there?"

Precious: "Two sticks."

Teacher: "Are they two sticks?"

Precious: "Yes."

Teacher: "One, two, three. Three magic wands."

In the 13 activities (with a total duration of 03:51:10) focal child Precious (class 1) expresses only $10 \mathrm{C}-\mathrm{T}$ utterances: 
"What is that?" (during clothes \& satchels, 20150609)

"Please." (during snack time, 20150918)

"Miss, look. Miss" (during free play, 20151020)

"Two sticks." (during free play, 20151020)

"Yes." (during free play, 20151020)

"No." (during free play, 20151020)

"I'm ready." (during free play, 20151020)

"Miss." (during free play, 20151020)

"Ride a bicycle." (during circle time, 20160303)

"Your hair. His hair." (during clothes \& satchels, 20160303)

Both the quantity and the quality of focal child Ramiz' (class 1) individual interactions are low. There wasonly one verbal interactive moment with the teacher that showedsome qualitative aspects (free play on 20160121). Ramiz was making a puzzle with the teacher. The scene lasted about four minutes. The teacher asked Ramiz three questions about placing a piece of the puzzle and one question about how the task was proceeding. Ramiz never replied verbally:

Teacher: "This one where?"

Teacher: "Put it in."

Teacher: "Oh, easy."

Teacher: "And the little sheep? Take the sheep!"

Teacher: "No, that's not right, Ramiz. It doesn't fit."

Teacher: "Try here. Look."

Teacher: "Easy!"

Teacher: "Yes, easy."

Teacher: "Yes, bravo Ramiz, good! And the doggy?"

Teacher: "Good! Bravo Ramiz, super! No, here."

Teacher: "Yes, bravo, super!"

Teacher: "Good Ramiz."

Teacher: "Yes! Bravo! Wow. Now you have to try alone. Now alone. Like this."

Teacher: "C'mon Ramiz. Try!"

Teacher: "Turn it Ramiz." 
$(\ldots)$

Ramiz: "Cat."

$(\ldots)$

Teacher: "How are you proceeding, Ramiz?"

Teacher: "Try, Ramiz.”

In all of the 11 activities of Ramiz (with a total duration of $02: 54: 33$ ) 'cat' is the only word he speaks to the teacher. His other verbal utterances, towards classmates, are also limited: "Hello! Hello!" (during snack time on 20150506), something to his brother that we couldnot understand during snack time on 20150506, "Mais, non.” (during free play on 20150609) and "No!" (during free play on 20160121).

We observed few verbal peer interactions in general and in all 54 activities there were no $\mathrm{T}-\mathrm{C}$ interactions wherein the teacher stimulated peer interactions. When children were in the classroom as a group, they were instructed to be quiet and listen to the teacher. We never observed a teacher stimulating the children to ask other children for help or to do something together.

\section{Feedback}

We observed hardly any feedback in any of the activities. When feedback occurred, it was aimed at confirming a desired behavior of a child, mostly to the benefit of the organization of routines. Many individual utterances initiated by the children were neglected by the teacher. It was the teacher who decided which child got to say something and in most cases, also the frame of what was allowed to be said was determined by the teacher. There were moments when children wanted to speak, chat or to stand up and take the floor, for example during circle time. However, in most cases, the children were asked to be quiet. This practice was more to the advantage of children who already had a proficiency in Dutch (school) language skills. Their utterances were more easily recognized and valued by the teacher, which resulted in more opportunities to speak and to interact. Sometimes, they took the floor by speaking out loud in a way that the teacher appreciated, even when they broke the be-quiet-rule by doing so. A salient example was the snack time from class 1 on 20150918. The children were having a snack in the corner of the classroom where also the circle time moments were held. Pan flute music was playing and the children had to be quiet. When a child was ready, he or she had to wait in silence 
on the bench until the rest of the group was ready. The teacher paid extra attention to this and rebuked the children when they were not silent enough. She also verbally stimulated the children to continue and to hurry up with their snack. The most common utterances of the teacher were "Shush", "Good", "Thumbs up" and "Continue eating". A nonverbal interaction between focal child Precious and another girl (Maya) occurred. Both children looked at each other, made funny faces and laughed. Even though they hardly made a sound, the teacher reprimanded focal child Precious: "Shush, Precious!". She did not address Maya. One minute later, another girl (Ante) asked and got the floor:

Ante: "Miss

Teacher: "Yes, Ante?"

Ante: "I ate an ice-cream with my granny."

Teacher: "Did you eat ice-cream with your granny?"

Ante: "Yes, with chocolate."

Teacher: "With chocolate?"

Ante: "Yes, at home."

Teacher: "At home? In the house of your granny or in your house?"

Ante: "With my granny."

Teacher: "With your granny. So she has ice-cream in the house? Wow!"

Ante: "One ice-cream, not two!"

Teacher: "No, not two!"

This scene suggests that Ante (withgood Dutch language skills) was privileged above the other children: she was granted with the opportunity to speak because of her assertiveness and her skills. Many children in the class had fewer Dutch language skills than Ante. They might have benefited more from such a conversation, yet they were not granted these opportunities.

We also frequently observed an ending of an interaction with a focal child in favor of an interaction with another child, thus hindering opportunities for language-rich conversations with the focal child. For example, while putting on the coats, focal child Yano of class 4 was called by the teacher for support with his coat. "Yes, come here, Yano!". This could have been a perfect occasion for an individual verbal interaction between the teacher and him and this may very well have been the intention of the teacher. However, other children came demanded the teacher's 
attention and received it. Yano,in turn,did not claim personal attention and remained quiet, missing the opportunity for interaction. As another example, during free play in class 3 , the teacher wanted to explain something to focal child Hanna when another child, Lena engaged in a conversation with the teacher. Because the teacher gave priority to Lena, focal child Hanna waited in silence.

\section{Discussion}

High expectations are set for pre-primary education as powerful equalizing opportunities for migrant children and their development in general and their language development in particular. However, the setting and working conditions of local ECEC contexts may seriously affect the teacher's potential to meet these expectations. The typically large groups with their specific group composition, separating the youngest children from their older peers, have downsides that may be considered challenging for teachers. In their transition to school, most children are unfamiliar with the ins and outs of their class and its daily routines and have no experienced peers to socialize them. The caring needs of the children leave the single teacher with a handful of caring tasks that are remarkably often not considered 'her job'. Indeed, one of the consequences of organizing ECEC as a split system and of the narrow focus on preschool as early learning, is that care and education are considered two distinct concepts entailing separate tasks to be executed by different people in different services. The Flemish pre-primary educational system may serve as an example of such an emphasis on education comprising a narrow interpretation of learning (Authors own, 2018). Consequently, teachers do not recognize caring moments as learning moments and therefore tend to focus more on group management. The teachers in our study focused on teaching routines aiming to include and socialize children as soon as possible. However, the focus on structure and routine, as a result of the focus on early learning, paradoxically seemed to be at odds with the learning possibilities of each child.

Our observations also suggest that tumult and noise may deepen existing inequalities. Indeed, children have to combine verbal assertiveness with the active knowledge of the school language and routines to be able to rise above the tumult and obtain rich verbal interactions with the teacher. Invitations or attempts of children who are more insecure, verbally less assertive or hesitant are often overlooked in the turmoil. This grants the already privileged children (i.e.whouse the school language at home) with more opportunities for meaningful interactions 
with the teacher. Conversely, most remarks, reprimands or restrictions go to children that have difficulties in understanding routines and the school language. Because of the focus on group management and structure, there is a lack of additional attention for the children with more caring needs. Paradoxically, children who are less familiar with the school language and its routines have to rely more on their own and are often left on their own to learn the structure and the routines. Consequently, they are held responsible for their own learning process. Moreover, we never observed a teacher stimulating a child to ask other children for help or to do something together. The children in our study missed opportunities and were not encouraged to care for each other and to learn from one another. Considering the low number of verbal peer interactions, children were mainly dependent on the teacher to further their Dutch language skills. The one-onone situations with the teacher are therefore paramount. Yet, they did not occur for each child during each activity and when they occurred, these one-on-one situations were short and did not provoke verbal interaction. There were hardly any conversational turns consisting of more than a closed question followed by a short answer. Moreover, we only found few examples where the teachers expanded the vocabulary of the children in an individual interaction. The most extensive conversations took place in interactions with children who already possessed adequate Dutch language skills.

Seven of the eight focal children were multilingual, yet this was hardly visible in the four classes. The home languages of the children were not valued and the few examples where teacher used a home language in individual interactions were intended to better direct the behavior of the children. The full potential of including multilingualism in the class practice was never reached, nor was it used to expand meaningful learning experiences for the children.

\section{Conclusion}

Part of the problem...

The aim of the present study was to examine the first school experiences of children at risk of social exclusion. Driven by the growing number of longitudinal studies which show positive effects of preschool attendance, this study was designed to unravel the emergence of learning opportunities for the youngest children in the Flemish pre-primary education system. The results point in the direction of a paradox. While it is often easily assumed that preschools matter and may contribute to reducing inequalities in education, the findings suggest that 
preschools may also be part of the problem, rather than of the solution. Classroom interaction of high quality and a rich verbal interaction climate is pivotal to enhance language learning. However, our study suggests that this potential is not always reached. Both the quantity and the quality of individual verbal interactions was found to be low and the opportunities for children's language production were very scarce. This was especially true for children with a home language different from the dominant one in the schools. The feedback they received was almost inexistent and often interrupted by children with more skills in the dominant language. According to the meta-study of Hattie (2009), quality of feedback is essential for learning.

\section{...or part of the solution?}

This suggests that mere attendance at preschool might reproduce or even increase the existing inequalities when poor verbal classroom interaction quality is observed. It shows the importance of professionalising and coaching preschool professionals, especially in contexts of increasing diversity and migration. However, it also shows the importance of the systemic conditions in which early years' professionals are at work. What is really needed are competent ECEC-systems beyond the individual competencies (Urban et al., 2011). Necessary preconditions for enabling competent systems are cooperation and appreciation among colleagues, accompanied by child-free hours that facilitate group reflection and supported by the active involvement of team leaders or principals (Author's own, 2018). When professionals are given opportunities of collegial consult, to observe and critically reflect upon each other's practice and build strong relationships with the community and the parents, they can break down the walls of their own classrooms and evolve together with their team towards a professional learning community that fosters both wellbeing and learning opportunities for all children and their families (Sharmahd et al., 2017).

\section{Limitations of the present study}

A major limitation of this study is the small scale of the study. Data collected on the experiences of eight children cannot be generalised nor are they representative for the whole population of toddlers starting school. Moreover, only four types of activities were selected for the analysis of individual verbal interactions. To fully grasp the learning opportunities, more detailed observations and analysis of interactional practices at a micro level are necessary. A second weakness of the study is the fact that we did not use validated instruments like CLASS or CIP. Because of the specificity of the data and in line with the research objectives, a self- 
constructed framework - having made use of an array of validated instruments - for the evaluation of verbal interactions was used.

Notwithstanding these limitations, by integrating qualitative and quantitative data we were able to have a glimpse in the black box of what really happens in preschool classes and unravel micro mechanisms that potentially might enforce existing inequalities. 


\section{References}

Becker, B., Klein, O., \& Biedinger, N. (2013). The Development of Cognitive, Language, and Cultural Skills From Age 3 to 6: A Comparison Between Children of Turkish Origin and Children of Native-Born German Parents and the Role of Immigrant Parents' Acculturation to the Receiving Society. American Educational Research Journal, 50(3), 616-649. doi:10.3102/0002831213480825

Bogaert, E., Gheeraert, E., Estercam, I., Boeckx, J., Bylois, L., \& Peeters, V. (2015). Minimaal Maxitaal. Leuven: Garant Uitgevers n.v.

Brilli, Y., Del Boca, D., \& Pronzato, C. (2011).Exploring the impacts of public childcare on mothers and children in Italy: does rationing play a role? IZA Discussion Paper (5918).

Caille, J.-P. (2001). Scolarisation à 2 ans et réussite de la carrière scolaire au début de l'école élémentaire. Éducation et formations, 7-18.

Danhier, J., \& Jacobs, D. (2017). Segregatie in het Onderwijs Overstijgen. Analyse van de resultaten van het PISA 2015-onderzoek in Vlaanderen en in de Federatie WalloniëBrussel.Brussel: Koning Boudewijnstichting.

DeKeyser, R. (2007). Practice in a second language: Perspectives from applied linguistics and cognitive psychology. Cambridge: Cambridge University Press.

Department of Education and Training. (2016). Onderzoek naar Kleuterparticipatie. Brussel: Vlaams Ministerie van Onderwijs en Vorming.

Ellis, R. (2005). Principles of instructed language learning. System, 7(2), 209-224. doi:10.1016/j.system.2004.12.006

European Commission. (2018). Council Recommendation on High Quality Early Childhood Education and Care Systems. SWD(2018) 173. Brussels: European Commission.

Felfe, C., \& Lalive, R. (2018). Does early child care affect children's development? Journal of Public Economics, 159, 33-53. doi:10.1016/j.jpubeco.2018.01.014

García, O., \& Wei, L. (2014). Translanguaging: Language, bilingualism and education. New York: Palgrave Macmillan.

Hattie, J.(2009). Visible Learning: A Synthesis of over 800 Meta Analyses relating to Achievement.London: Routledge.

Hedges, H., \& Cullen, J. (2012). Participatory learning theories: A framework for early childhood pedagogy. Early Child Development and Care, 182(7), 921-940.

Jacobs, D., Rea, A., Teney, C., Callier, L., \& Lothaire, S. (2009). De sociale lift blijft steken. De prestaties van allochtone leerlingen in de Vlaamse Gemeenschap en de Franse Gemeenschap. Brussel: Koning Boudewijnstichting.

Jaffe, A. (2003). Talk around text: Literacy practices, cultural identity and authority in a Corsican bilingual classroom. International Journal of Bilingual Education and Bilingualism, 6(34), 202-220.

Jensen, B., Holm, A., \& Bremberg, S. (2013). Effectiveness of a Danish early year preschool program: A randomized trial. International Journal of Educational Research, 62, 115128. doi:10.1016/j.ijer.2013.06.004

La Paro, K. M., Hamre, B. K., \& Pianta, R. C. (2012). Classroom assessment scoring system (CLASS) manual, toddler. Lewisville: Paul H. Brookes Publishing Company.

Loman, J., Moons, C., \& Versteden, P. (2012). Taal de hele dag! Taal stimuleren tijdens dagelijkse routines. Nieuwsbrief TAAL \& ONDERWIJS, (14), 12. Retrieved from 
http://www.cteno.be/assets/downloads/cteno/nieuwsbrief/2012 14/nieuwsbrief_14 taalro utines.pdf

Magnuson, K. A., Meyers, M. K., Ruhm, C. J., \& Waldfogel, J. (2004). Inequality in preschool education and school readiness. American Educational Research Journal, 41(1), 115-157. doi:Doi 10.3102/00028312041001115

Marope, M., \& Kaga, Y. (2015). Repositioning ECCE in the post-2015 agenda. In M. Marope \& Y. Kaga (Eds.), Investing against Evidence. The Global State of Early Childhood Care and Education (pp. 9-33). Paris: UNESCO.

Moodley, V. (2007). Codeswitching in the multilingual English first language classroom. International Journal of Bilingual Education and Bilingualism, 10(6), 707-722.

OECD. (2017). Early learning matters. Paris: OECD.

Olivares, R. A., \& Lemberger, N. (2002). Identifying and applying the communicative and the constructivist approaches to facilitate transfer of knowledge in the bilingual classroom. International Journal of Bilingual Education and Bilingualism, 5(1), 72-83.

Olmedo, I. M. (2003). Language mediation among emergent bilingual children. Linguistics and education, 14(2), 143-162.

Ramaut, G., Sierens, S., Bultynck, K., Van Avermaet, P., Slembrouck, S., Van Gorp, K., \& Verhelst, M. (2013). Evaluatieonderzoek van het project'Thuistaal in onderwijs'(20092012): eindrapport maart 2013. Gent: Universiteit Gent.

Ramirez-Esparza, N., Garcia-Sierra, A., \& Kuhl, P. K. (2014). Look who's talking: speech style and social context in language input to infants are linked to concurrent and future speech development. Developmental Science, 17(6), 880-891. doi:10.1111/desc.12172

Robson, C. (2002). Real World Research: A Resource for Social Scientists and PractitionerResearchers (2nd ed.). Oxford: Blackwell Publishing.

Sabol, T. J., Hong, S. L. S., Pianta, R. C., \& Burchinal, M. R. (2013). Can Rating Pre-K Programs Predict Children's Learning? Science, 341(6148), 845-846. doi:10.1126/science. 1233517

Sammons, P., Sylva, K., Melhuish, E., Siraj-Blatchford, I., Taggart, B., Toth, K., Smees, R. (2012). Influences on students' attainment and progress in Key Stage 3: Academic outcomes in English, maths and science in Year 9. Effective Pre-School, Primary and Secondary Education Project (EPPSE 3-14).London: DfE.

Sharmahd, N., Peeters, J., van Laere, K., Vonta, T., De Kimpe, C., Brajković, S., Giovannini, D. (2017). Transforming European ECEC Services and Primary Schools Into Professional Learning Communities: Drivers, Barriers and Ways Forward: NESET II: Analytical Report (9279700812). Retrieved from Luxembourg:

Slot, P. L., Lerkkanen, M., \& Leseman, P. P. (2015). The relations between structural quality and process quality in European early childhood education and care provisions: Secondary analyses of large scale studies in five countries. (CARE Project). Utrecht: Utrecht University.

Slot, P. (2018). Structural characteristics and process quality in early childhood education and care: A literature review. OECD Education Working Papers, No. 176. Paris: OECD Publishing. 


\section{Tables}

Table 1: indicators for the qualitative analysis of teacher - child interactions

\begin{tabular}{|l|l|}
\hline $\begin{array}{l}\text { Language input } \\
\text { (L.I.) }\end{array}$ & $\begin{array}{l}\text { Rich: spontaneous, natural, varied, limited amount of } \\
\text { diminutives, using full sentences, articulate actions and thinking } \\
\text { processes, challenging children to use new vocabulary } \\
\text { Understandable: making a connection between language and } \\
\text { actions and objects, repeating and paraphrasing, alternating and } \\
\text { good intonation } \\
\text { Connected to the lifeworld and knowledge of the child, its } \\
\text { vocabulary and concepts }\end{array}$ \\
\hline $\begin{array}{l}\text { Opportunities for } \\
\text { language }\end{array}$ & $\begin{array}{l}\text { Using open ended questions } \\
\text { Stimulating the child to analyse and to reason and stimulating its } \\
\text { capacities for problem solving and reflection } \\
\text { Stimulating mutual interaction between children } \\
\text { Stimulating informal interaction }\end{array}$ \\
\hline Feedback & $\begin{array}{l}\text { Giving clues and help } \\
\text { Posing supportive questions } \\
\text { Responding to questions with new questions } \\
\text { Giving stimulating comments } \\
\text { Giving extra information after a response } \\
\text { Challenging the child to articulate actions and to put deeds into } \\
\text { words }\end{array}$ \\
\hline
\end{tabular}


Table 2: Overview selected activities ${ }^{2}$

\begin{tabular}{|c|c|c|c|c|c|c|c|c|c|c|c|c|}
\hline & \multicolumn{3}{|c|}{ Class 1} & \multicolumn{3}{|c|}{ Class 2} & \multicolumn{3}{|c|}{ Class 3} & \multicolumn{3}{|c|}{ Class 4} \\
\hline & $\mathbf{N}$ & Averagelength & SD & $\mathbf{N}$ & Averagelength & SD & $\mathbf{N}$ & Averagelength & SD & $\mathbf{N}$ & Averagelength & SD \\
\hline Circle time & 4 & $0: 10: 56$ & $0: 04: 33$ & 3 & $0: 16: 51$ & $0: 07: 40$ & 5 & $0: 13: 44$ & $0: 11: 28$ & 4 & $0: 12: 37$ & $0: 08: 52$ \\
\hline Free play & 4 & $0: 32: 25$ & 0:06:04 & 4 & $0: 29: 17$ & 0:07:12 & 3 & $0: 27: 08$ & 0:05:18 & 4 & $0: 39: 31$ & $0: 02: 48$ \\
\hline Snack time & 3 & $0: 22: 10$ & $0: 02: 37$ & 3 & $0: 16: 21$ & 0:03:47 & 2 & $0: 13: 34$ & $0: 04: 23$ & 3 & $0: 24: 08$ & 0:02:00 \\
\hline Clothes\&Satchels & 3 & 0:08:38 & 0:03:46 & 4 & $0: 08: 22$ & $0: 02: 48$ & 2 & $0: 03: 22$ & 0:00:08 & 3 & $0: 10: 17$ & 0:03:38 \\
\hline
\end{tabular}

${ }^{2}$ Except for class 1 and class 2,the specific number of activities (N) goes for both the focal children in the classes. Focal child 1 of class 1 had three free play moments instead of four, focal child 2 had two free play moments instead of four and three snack times instead of four. Focal child 1 of class 2 had three free play moments instead of four, two snack times instead of three and three clothes \& satchel moments instead of four. 
Table 3: Quantity of individual utterances

\begin{tabular}{|c|c|c|c|c|c|c|c|c|c|c|}
\hline & \multirow[b]{2}{*}{ Activity } & \multirow[b]{2}{*}{$\begin{array}{l}\text { Interaction } \\
\text { Mode }\end{array}$} & \multicolumn{4}{|c|}{ Focal Child X } & \multicolumn{4}{|c|}{ Focal Child Y } \\
\hline & & & $\begin{array}{c}\text { Total Number of } \\
\text { Utterances }\end{array}$ & $\begin{array}{c}\text { Total } \\
\text { Duration }\end{array}$ & $\begin{array}{c}\text { Average / } \\
\text { Activity }\end{array}$ & $\begin{array}{c}\text { AverageDuration } \\
\text { / Activity }\end{array}$ & $\begin{array}{l}\text { Total Number of } \\
\text { Utterances }\end{array}$ & $\begin{array}{c}\text { Total } \\
\text { Duration }\end{array}$ & $\begin{array}{c}\text { Average / } \\
\text { Activity }\end{array}$ & $\begin{array}{r}\text { AverageDura } \\
\text { / Activity }\end{array}$ \\
\hline \multirow{20}{*}{ Class 1} & \multirow{5}{*}{ Circle Time } & T-FC & 11 & $0: 00: 36$ & 2,8 & $0: 00: 03$ & 13 & $0: 00: 59$ & 3,3 & $0: 00: 05$ \\
\hline & & FC-T & 1 & 0:00:01 & 0,3 & 0:00:01 & 0 & 0:00:00 & 0 & 0:00:00 \\
\hline & & $\mathrm{C}-\mathrm{FC}$ & 0 & 0:00:00 & 0 & 0:00:00 & 0 & 0:00:00 & 0 & 0:00:00 \\
\hline & & FC-C & 0 & 0:00:00 & 0 & 0:00:00 & 0 & 0:00:00 & 0 & 0:00:00 \\
\hline & & Total & 12 & 0:00:37 & 3 & 0:00:03 & 13 & 0:00:59 & 3,3 & 0:00:01 \\
\hline & \multirow{5}{*}{ Free Play } & $\mathrm{T}-\mathrm{FC}$ & 23 & $0: 01: 17$ & 7,7 & 0:00:03 & 34 & $0: 01: 28$ & 17 & 0:00:03 \\
\hline & & FC-T & 6 & 0:00:03 & 2 & 0:00:01 & 1 & 0:00:00 & 0,5 & 0:00:00 \\
\hline & & $\mathrm{C}-\mathrm{FC}$ & 12 & $0: 00: 49$ & 4 & 0:00:04 & 2 & 0:00:07 & 1 & 0:00:04 \\
\hline & & FC-C & 14 & 0:00:44 & 4,7 & 0:00:03 & 2 & 0:00:02 & 1 & 0:00:01 \\
\hline & & Total & 55 & 0:02:53 & 18,3 & 0:00:03 & 39 & 0:01:37 & 19,5 & 0:00:02 \\
\hline & \multirow{5}{*}{ Snack Time } & $\mathrm{T}-\mathrm{FC}$ & 32 & $0: 01: 48$ & 10,7 & 0:00:03 & 16 & $0: 00: 32$ & 8 & $0: 00: 02$ \\
\hline & & FC-T & 1 & 0:00:00 & 0,3 & 0:00:00 & 0 & 0:00:00 & 0 & 0:00:00 \\
\hline & & $\mathrm{C}-\mathrm{FC}$ & 1 & 0:00:03 & 0,3 & 0:00:03 & 0 & 0:00:00 & 0 & 0:00:00 \\
\hline & & FC-C & 1 & 0:00:08 & 0,3 & 0:00:08 & 2 & 0:00:07 & 1 & 0:00:04 \\
\hline & & Total & 35 & 0:01:59 & 11,7 & 0:00:03 & 18 & 0:00:39 & 9 & 0:00:02 \\
\hline & \multirow{5}{*}{ Clothes\&Satchels } & T-FC & 15 & $0: 00: 51$ & 5 & $0: 00: 03$ & 8 & $0: 00: 43$ & 2,7 & 0:00:05 \\
\hline & & FC-T & 2 & 0:00:03 & 0,7 & 0:00:02 & 0 & 0:00:00 & 0 & 0:00:00 \\
\hline & & $\mathrm{C}-\mathrm{FC}$ & 0 & 0:00:00 & 0 & 0:00:00 & 0 & 0:00:00 & 0 & 0:00:00 \\
\hline & & FC-C & 0 & 0:00:00 & 0 & 0:00:00 & 0 & 0:00:00 & 0 & 0:00:00 \\
\hline & & Total & 17 & 0:00:54 & 5,7 & 0:00:03 & 8 & 0:00:43 & 2,7 & 0:00:05 \\
\hline \multirow{20}{*}{ Class 2} & \multirow{5}{*}{ Circle Time } & $\mathrm{T}-\mathrm{FC}$ & 9 & $0: 00: 39$ & 3 & $0: 00: 04$ & 24 & $0: 01: 38$ & 8 & $0: 00: 04$ \\
\hline & & FC-T & 4 & 0:00:04 & 1,3 & 0:00:01 & 3 & 0:00:03 & 1 & 0:00:01 \\
\hline & & $\mathrm{C}-\mathrm{FC}$ & 0 & 0:00:00 & 0 & 0:00:00 & 0 & 0:00:00 & 0 & 0:00:00 \\
\hline & & FC-C & 0 & 0:00:00 & 0 & 0:00:00 & 0 & 0:00:00 & 0 & 0:00:00 \\
\hline & & Total & 13 & 0:00:43 & 4,3 & 0:00:03 & 27 & 0:01:41 & 9 & 0:00:04 \\
\hline & \multirow{5}{*}{ Free Play } & T-FC & 49 & $0: 03: 13$ & 16,3 & $0: 00: 04$ & 43 & $0: 02: 28$ & 10,8 & $0: 00: 03$ \\
\hline & & FC-T & 20 & 0:00:30 & 6,7 & 0:00:02 & 8 & 0:00:05 & 2 & 0:00:01 \\
\hline & & $\mathrm{C}-\mathrm{FC}$ & 12 & $0: 00: 20$ & 4 & 0:00:02 & 21 & 0:00:40 & 5,3 & 0:00:02 \\
\hline & & FC-C & 16 & $0: 00: 25$ & 5,3 & 0:00:02 & 22 & 0:01:01 & 5,5 & 0:00:03 \\
\hline & & Total & 97 & 0:04:28 & 32,3 & 0:00:03 & 94 & 0:04:14 & 23,5 & 0:00:03 \\
\hline & \multirow{5}{*}{ Snack Time } & T-FC & 26 & 0:01:06 & 13 & 0:00:03 & 21 & $0: 00: 54$ & 7 & 0:00:03 \\
\hline & & FC-T & 3 & 0:00:02 & 1,5 & 0:00:01 & 3 & 0:00:00 & 1 & 0:00:00 \\
\hline & & $\mathrm{C}-\mathrm{FC}$ & 1 & 0:00:01 & 0,5 & 0:00:01 & 2 & 0:00:07 & 0,7 & 0:00:04 \\
\hline & & FC-C & 2 & 0:00:07 & 1 & 0:00:04 & 1 & 0:00:01 & 0,3 & 0:00:01 \\
\hline & & Total & 32 & 0:01:16 & 16 & 0:00:02 & 27 & 0:01:02 & 9 & 0:00:02 \\
\hline & \multirow{5}{*}{ Clothes\&Satchels } & T-FC & 27 & $0: 01: 36$ & 9 & 0:00:04 & 27 & $0: 01: 16$ & 6,8 & $0: 00: 03$ \\
\hline & & FC-T & 2 & 0:00:04 & 0,7 & 0:00:02 & 1 & 0:00:01 & 0,3 & 0:00:01 \\
\hline & & $\mathrm{C}-\mathrm{FC}$ & 9 & $0: 00: 25$ & 3 & 0:00:03 & 6 & $0: 00: 13$ & 1,5 & 0:00:02 \\
\hline & & FC-C & 7 & 0:00:19 & 2,3 & 0:00:03 & 9 & $0: 00: 25$ & 2,3 & 0:00:03 \\
\hline & & Total & 45 & 0:02:24 & 11,3 & 0:00:03 & 43 & 0:01:55 & 10,8 & 0:00:03 \\
\hline \multirow{10}{*}{ Class 3} & \multirow{5}{*}{ Circle Time } & $\mathrm{T}$-FC & 60 & $0: 03: 20$ & 12 & 0:00:03 & 24 & $0: 01: 06$ & 4,8 & $0: 00: 03$ \\
\hline & & FC-T & 13 & $0: 00: 17$ & 2,6 & 0:00:01 & 4 & 0:00:06 & 0,8 & 0:00:02 \\
\hline & & $\mathrm{C}-\mathrm{FC}$ & 1 & 0:00:04 & 0,2 & 0:00:04 & 1 & 0:00:02 & 0,2 & 0:00:02 \\
\hline & & FC-C & 0 & 0:00:00 & 0 & 0:00:00 & 0 & 0:00:00 & 0 & 0:00:00 \\
\hline & & Total & 74 & 0:03:41 & 14,8 & 0:00:03 & 29 & 0:01:14 & 5,8 & 0:00:03 \\
\hline & \multirow{5}{*}{ Free Play } & T-FC & 28 & $0: 01: 57$ & 9,3 & 0:00:04 & 22 & $0: 02: 16$ & 7,3 & 0:00:06 \\
\hline & & FC-T & 8 & $0: 00: 15$ & 2,7 & 0:00:02 & 10 & 0:00:09 & 3,3 & 0:00:01 \\
\hline & & $\mathrm{C}-\mathrm{FC}$ & 0 & 0:00:00 & 0 & 0:00:00 & 5 & $0: 00: 25$ & 1,7 & 0:00:05 \\
\hline & & FC-C & 3 & 0:00:19 & 1 & 0:00:06 & 4 & $0: 00: 16$ & 1,3 & 0:00:04 \\
\hline & & Total & 39 & 0:02:31 & 13 & 0:00:04 & 41 & 0:03:06 & 13,7 & 0:00:05 \\
\hline
\end{tabular}




\begin{tabular}{|c|c|c|c|c|c|c|c|c|c|c|}
\hline & \multirow{5}{*}{ Snack Time } & $\mathrm{T}-\mathrm{FC}$ & 20 & 0:00:55 & 10 & 0:00:03 & 12 & 0:00:51 & 6 & 0:00:04 \\
\hline & & FC-T & 11 & $0: 00: 32$ & 5,5 & 0:00:03 & 1 & 0:00:02 & 0,5 & $0: 00: 02$ \\
\hline & & C-FC & 0 & 0:00:00 & 0 & 0:00:00 & 0 & 0:00:00 & 0 & 0:00:00 \\
\hline & & FC-C & 0 & 0:00:00 & 0 & 0:00:00 & 0 & 0:00:00 & 0 & 0:00:00 \\
\hline & & Total & 31 & 0:01:27 & 15,5 & 0:00:03 & 13 & $0: 00: 53$ & 6,5 & 0:00:04 \\
\hline & \multirow{5}{*}{ Clothes\&Satchels } & $\mathrm{T}-\mathrm{FC}$ & 8 & $0: 00: 29$ & 4 & 0:00:04 & 4 & $0: 00: 20$ & 2 & 0:00:05 \\
\hline & & FC- $T$ & 0 & 0:00:00 & 0 & 0:00:00 & 0 & 0:00:00 & 0 & 0:00:00 \\
\hline & & C-FC & 0 & 0:00:00 & 0 & 0:00:00 & 0 & 0:00:00 & 0 & $0: 00: 00$ \\
\hline & & FC-C & 0 & 0:00:00 & 0 & 0:00:00 & 0 & 0:00:00 & 0 & 0:00:00 \\
\hline & & Total & 8 & 0:00:29 & 4 & 0:00:04 & 4 & 0:00:20 & 2 & 0:00:05 \\
\hline \multirow{20}{*}{ Class 4} & \multirow{5}{*}{ Circle Time } & $T-F C$ & 6 & 0:00:17 & 1,5 & 0:00:03 & 10 & 0:00:46 & 2,5 & 0:00:05 \\
\hline & & FC-T & 1 & 0:00:03 & 0,3 & 0:00:03 & 0 & 0:00:00 & 0 & 0:00:00 \\
\hline & & C-FC & 0 & 0:00:00 & 0 & 0:00:00 & 0 & 0:00:00 & 0 & 0:00:00 \\
\hline & & FC-C & 0 & 0:00:00 & 0 & 0:00:00 & 3 & 0:00:08 & 0,8 & 0:00:03 \\
\hline & & Total & 7 & $0: 00: 20$ & 1,8 & 0:00:03 & 13 & $0: 00: 54$ & 3,3 & 0:00:04 \\
\hline & \multirow{5}{*}{ Free Play } & T-FC & 6 & 0:00:15 & 1,5 & 0:00:02 & 44 & $0: 04: 15$ & 11 & 0:00:06 \\
\hline & & FC-T & 4 & 0:00:04 & 1 & 0:00:01 & 6 & 0:00:05 & 1,5 & 0:00:01 \\
\hline & & C-FC & 1 & 0:00:04 & 0,3 & 0:00:04 & 1 & 0:00:01 & 0,3 & 0:00:01 \\
\hline & & FC-C & 1 & 0:00:08 & 0,3 & 0:00:08 & 1 & 0:00:01 & 0,3 & 0:00:01 \\
\hline & & Total & 12 & $0: 00: 31$ & 3 & 0:00:03 & 52 & $0: 04: 22$ & 13 & 0:00:05 \\
\hline & \multirow{5}{*}{ Snack Time } & T-FC & 29 & 0:01:12 & 9,7 & 0:00:02 & 30 & 0:01:21 & 10 & 0:00:03 \\
\hline & & FC- $T$ & 5 & 0:00:07 & 1,7 & 0:00:01 & 0 & 0:00:00 & 0 & 0:00:00 \\
\hline & & C-FC & 0 & 0:00:00 & 0 & 0:00:00 & 0 & 0:00:00 & 0 & 0:00:00 \\
\hline & & FC-C & 0 & 0:00:00 & 0 & 0:00:00 & 0 & 0:00:00 & 0 & 0:00:00 \\
\hline & & Total & 34 & 0:01:19 & 11,3 & 0:00:02 & 30 & 0:01:21 & 10 & 0:00:03 \\
\hline & \multirow{5}{*}{ Clothes\&Satchels } & T-FC & 14 & $0: 00: 38$ & 4,7 & 0:00:03 & 7 & $0: 00: 22$ & 2,3 & 0:00:03 \\
\hline & & FC-T & 3 & 0:00:04 & 1 & 0:00:01 & 0 & 0:00:00 & 0 & 0:00:00 \\
\hline & & C-FC & 0 & 0:00:00 & 0 & 0:00:00 & 0 & 0:00:00 & 0 & 0:00:00 \\
\hline & & FC-C & 1 & 0:00:03 & 0,3 & 0:00:03 & 0 & 0:00:00 & 0 & 0:00:00 \\
\hline & & Total & 18 & $0: 00: 45$ & 6 & 0:00:02 & 7 & $0: 00: 22$ & 2,3 & 0:00:03 \\
\hline
\end{tabular}


Table 4: Quality of individual TC interactions

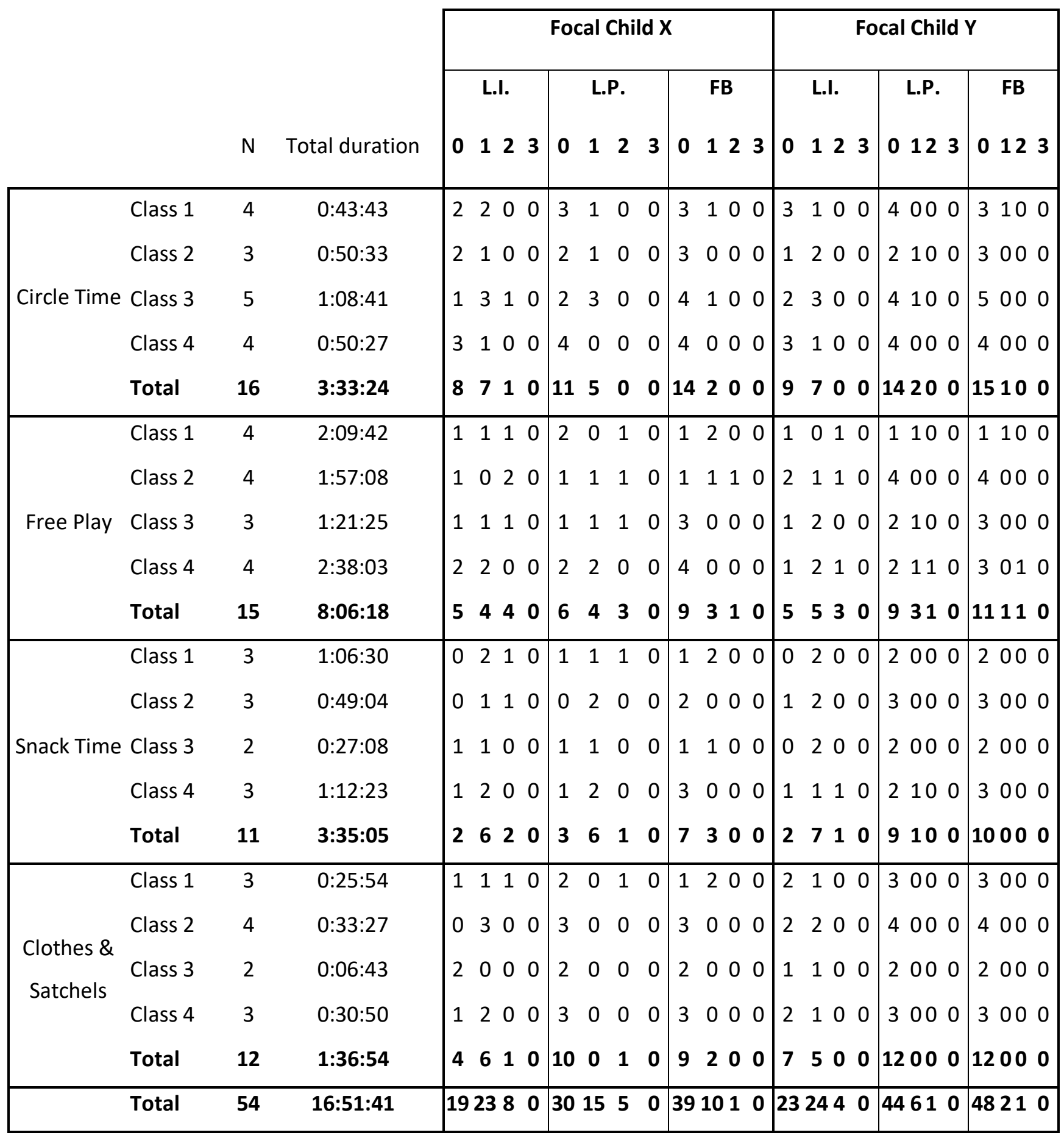


